\title{
Prevalence and Associated Factors of Dental Caries among Basic School Children in Kathmandu Metropolitan City, Nepal: A Cross-sectional Study.
}

\author{
Mahendra Giri1,2 *, Shailesh Kumar Pandit ${ }^{3}$,Hari Prasad Oli ${ }^{4}$,Sujata Giri1 \\ ${ }^{1}$ Innovative Foundation for Health and Research (IFHR), Kathmandu, Nepal, ${ }^{2}$ Department of Social Welfare, Health \\ Section, Lalitpur Metropolitan City Office, Pulchwok, Lalitpur, Nepal, ${ }^{3}$ Ministry of Social Welfare Bagmati Province, \\ Provincial Health Directorate, Health Office Kathmandu, Teku, Kathmandu,Nepal, ${ }^{4}$ Kantipur Dental College Teaching \\ Hospital and Research Center, Kathmandu, Nepal.
}

\section{ARTICLE INFO \\ Article history: Received: 17 March 2021 Revised: 11 May 2021 Accepted: 23 June 2021 \\ *Correspondence: Mr. Mahendra Giri Innovative Foundation for Health and Research (IFHR), Kathmandu, Nepal. \\ E-mail: \\ mdr.giri21@gmail.com, mahendra.giri@noc.edu.np \\ ORCID: 0000-0002-3895-9861 \\ Citation: Giri M, Pandit SK, Oli HP, Giri S. Prevalence and Associated Factors of Dental Caries among Basic School Children in Kathmandu Metropolitan City, Nepal: A Cross-sectional Study. MedS. J. Med. Sci. 2021;1(1):89-94}

\begin{abstract}
ABSTARCT
INTRODUCTION: Oral health problems of school children are one of the most common health related problem in the world. . The prevalence of dental caries is significantly higher in school children. In Nepal, the morbidity of dental caries is very high among school children compared to other age groups. Dental caries is neglected at initial stages in children, but when the disease becomes progressive the treatment options being one of the most expensive and unaffordable. This study sought to identity the prevalence and associated risk factors of dental caries among basic school children age group from 6-12 years. MATERIALS AND METHODS: Analytical crosssectional study design was carried out among school children. . A semi-structured questionnaire was developed and face to face interview method was used to collect information from two public schools and two private schools of Kathmandu metropolitan City. Purposive sampling technique was applied. DMFT (Decayed, Missed, Filled, Teeth) index was adopted to measure mixed dentition, and also to assess the oral health status of school children. The collected data was entered and analyzed using IBM SPSS-20. RESULTS: Among 274 participants, there were equal number of female and male students (Female: 137, Male: 137), likewise the number of participants from public and private school was also equal. The prevalence of dental caries among school children was found to be $55.84 \%$ and there was significant association between frequency of brushing with dental caries ( $\mathrm{p}=0.001) .176(64.2 \%)$ of the participants consumed normal food, 56 (20.4\%) consumed junk food and $39(14.2 \%)$ consumed spicy food. The consumption of different food types played a significant role in the occurrence of dental caries. CONCLUSIONS: Frequency of brushing and types of food consumption are significantly associated with the higher prevalence of dental caries among school children. Regular dental check-up and good brushing practice can reduce the prevalence of dental caries in school children. Hence, continuous oral health programs including demonstration of proper brushing technique along with oral health awareness programs at school can help to reduce the burden of dental caries among school children.
\end{abstract}

KEY WORDS: Dental caries, oral health, prevalence, school health

\section{INTRODUCTION}

Dental caries is still a common disease among children and adolescents. Dental caries is one of the most prevalent chronic diseases in human beings worldwide. It is a multi-factorial disease that starts with microbiological shifts within the complex biofilm (dental plaque). Dental caries is affected by the consumption of dietary sugars, salivary flow, exposure to fluoride and preventive behaviour [1].
Poor oral health has a significant effect on general health and several oral diseases are related to chronic diseases. The experience of pain, problems with eating, chewing, smiling and communication due to missing, discoloured and damaged teeth have a major impact on people's daily lives and well- being. Oral diseases also cause problems at school, at work and at home leading to loss of 
working hours each year throughout the world [2]. Dental caries is caused by imbalance between tooth minerals and biofilm which is also commonly known as plaque. Generally, dental plaque is caused by bacterial acid production and buffering action of saliva and surrounding tooth structures which ultimately causes demineralization of enamel, dentin and cementum of tooth structure resulting into dental caries [3]. After intake of carbohydrates, streptococcus mutans cause formation of acids that dissolves the minerals of enamel and dentine. Dental caries causes tooth pain, discomfort, eating impairment, loss of tooth and delay language development. Further- more dental caries has effects on children concentration in school and increases financial burden of the families. Risk factors such as age, sex, dietary habits, socioeconomic and oral hygiene status are associated with increased prevalence and incidence of dental caries in population [4].

For oral health of children, 12 years of age has been the object of several epidemiological studies conducted around the world. According to World Health Organization (WHO), the importance given to this age group is because at this age, children leave primary school. Thus in many countries, it is the last age at which data can be easily obtained as reliable sample from the school system. It is also the age at which all the permanent teeth except third molars are already erupted. Thus, the age of 12 years was determined as the age for global monitoring of caries for international comparisons and monitoring of disease trends. The DMFT (Decayed, Missed, Filled, Teeth) index is the common outcome for such studies [5]. DMFT index and Decayed, Missing and Filled surface (DMFS) are the standardized and universally accepted indices for measuring caries in a population (2). In 1983 oral health was declared as a part of the strategy "Health for all" and in 1989, WHO declared oral health as an integral part of "Health for all" by the year 2000. In addition, World Health Day in 1994 was dedicated to oral health, which also reflects the importance attached to this issue. Oral diseases like dental caries, periodontal disease, tooth loss, oral mucosal lesions, oro-pharyngeal cancers, human immunodeficiency virus/acquired immune deficiency syndrome (HIV/AIDS) related oral disease and oro-dental trauma are major public health problems worldwide [6,7].
Dental caries is considered as a major public health problem globally due to its high prevalence and significant social impact. WHO reports $60-90 \%$ of school children worldwide have experienced caries, with the disease being most prevalent in Asian and Latin American countries. In Nepal, nearly $41 \%$ of the total population is under the age of 16 years, and of the total school age children, $87 \%$ are only enrolled in school. The 2004 National Pathfinder Survey shows that $58 \%$ of 5 to 6 years old school children suffer from dental caries [8]. With the caries prevalence of $58 \%$, dental caries is more prevalent than malnutrition that affects $49 \%$ of child population [3]. Due to lack of health education and insufficient preventive measures, there is high prevalence and morbidity of dental caries and the health status of the student is not good [9].

Since, children are the future of nation, it is important to recognize the problem faced by children in the initial stages and develop appropriate preventive measures. In developing countries like Nepal, children are the most neglected groups in any kinds of research. The research based on oral hygiene and oral diseases are equally rare. Due to poor literacy rate in Nepal, people are not aware about the consequences of poor oral health condition. They are highly neglected in the initial stage and when the disease becomes progressive, the treatment options are highly unaffordable in developing countries like Nepal [8]. In developing countries like Nepal, there is big difference between students of private and public school. Low income family status students are admitted in public schools whereas middle to high income family status students are admitted in private schools. Children of private schools have higher incidence of dental caries as they consume more sticky and junk food, however, the incidence of dental caries is also high in public school children as they cannot afford tooth paste and tooth brush [7].

Different researches are conducted on life style and non-communicable diseases but in developed or developing countries there is low concern about conducting research or health camp for school children. Thus, this study was conducted as an attempt to promote oral health of school children by assessing oral health status and identifying the risk factors for dental caries. 


\section{MATERIALS AND METHODS}

Study design and setting

Analytical cross-sectional study design was carried out to find out the prevalence, and associate factors of dental carries among basic school children. Semi structured questionnaire were developed and face to face interview was carried out to collect information from basic school children at Kathmandu Metropolitan City. Schools were selected purposively amongst school located inside the Kathmandu metropolitan city. The numbers of schools were in 2 from private and 2 from public.

Participants, sampling and sample size

The sample size was calculated using the formula for the descriptive cross-sectional study, and the calculated sample size was 274. Among the sample size $(n=274)$, equal numbers $(n=137)$ of participants were selected conveniently from sample framed private and public school respectively. Children aged between 6-12 years, studying in basic school were included in this study but mentally retarded children were excluded from this study.

Data collection and study variables

Face to face interview was carried out to collect information from basic school children at Kathmandu Metropolitan City. DMFT (Decayed, Missed, Filled, Teeth) index was adopt to measure mixed dentition, and assess the oral health status of

\section{RESULTS}

\section{Sociodemographic characteristics}

In this study, out of 274 participants equal number $(n=137)$ of males and females were involved. $14.2 \%$ of the children were from 6 to 8 years of age, $29.6 \%$ were from 8 to 10 years of age and $56.2 \%$ were from 10 to 12 years of age. Majority of children were between 10 to 12 years of age $(56.2 \%)$, consumed normal food $(64.2 \%)$, used medium type of brush for brushing their teeth $(45.3 \%)$ and used fluoridated tooth paste for brushing their teeth $(56.9 \%)$. Almost two third of the children 179 (65.3\%) do not visit dentists at all, $53.6 \%$ children spent between 2-5 minutes for brushing their teeth, $54 \%$ children changed their brush in every six month and $46.72 \%$ children had bleeding while brushing their teeth (Table 1). school children [10]. Socio- demographic and income factor releted variables, clinical factor related variables, and predisposing factor related variables were used to conduct the study.

To maintain the quality of control and assurance of this study pre-test was done in a school, which had similar characteristics of sampled school for content validity and some modifications were made after the observation of pre-test results. Ethical approval was taken to conduct this study from the Ethical Review Board, Department of Public Health, North South University, Dhaka, Bangladesh (Approval no: 2020/OR-NSU/IRB-no.0803). Data collection permission was taken from Department of Education, Kathmandu metropolitan city office, Kathmandu and the respected schools. Informed written consent was taken during data collection and confidentiality of the participants was maintained.

\section{Statistical consideration}

The collected data was checked for completeness and was entered and analyzed using IBM SPSS version 20. The results were interpreted in terms of frequency of response and percentage. Chi-square test was adopted to find out the associated factors with various demographic and enabling factors.

\section{Association between frequency of dental visit} and dental caries Seventy six participants neither had dental caries nor did they visit dentist, 103 participants who had dental caries did not visit dentist. Among them 67 (24.5\%) who visited dentist once in a year, $42(62.69 \%)$ had dental caries and $25(37.31 \%)$ did not have the problem of dental caries. In bivariate analysis, from chisquare test, there was no association between frequency of dental visit and dental caries $(p=$ 0.007), however there was strong association between frequency of brushing and dental caries $(p=0.001)$ at 95 CI. Moreover, this study found that there was no association between pain in teeth and dental caries $(\mathrm{p}=0.008)$ (Table 2$)$. 
Table 2 I Association between socio-demographic factors and enabling factors of dental caries.

Characteristics Dental Caries PNo dental Dental Total value caries caries for Chi Square

Frequency of dental visit

\begin{tabular}{|c|c|c|c|c|}
\hline Not at all & 76 & 103 & 179 & \multirow{3}{*}{0.007} \\
\hline Once a year & 25 & 42 & 67 & \\
\hline Twice a year & 20 & 8 & 28 & \\
\hline \multicolumn{5}{|c|}{ equency of teeth brushing } \\
\hline No brushing & 4 & 9 & 13 & \multirow{3}{*}{0.0001} \\
\hline Once a day & 61 & 105 & 166 & \\
\hline Twice a day & 121 & 154 & 275 & \\
\hline \multicolumn{5}{|l|}{ Pain in teeth } \\
\hline Normal & 66 & 93 & 159 & \multirow{3}{*}{0.008} \\
\hline Moderate & 52 & 54 & 106 & \\
\hline Severe & 4 & 6 & 10 & \\
\hline
\end{tabular}

\section{DISCUSSION}

The modern industrial world has been improving in holistic way. Despite of great improvements in the oral health of population in several countries, it is claimed that poor oral health may have a deep effect on general health, several oral diseases related to chronic diseases as well as value of life [11]. Present study tries to explore the prevalence of dental caries and its associated factors like frequency of brushing, their food habit and their parent's education and income level among school children aged 6-12 years of 2 private and 2 public school of Kathmandu metropolitan city.

The prevalence of dental caries was 55.84\% among school going children of aged 6-12 years, which may be because of poor oral hygiene and consumption of junk food. Many studies found that prevalence and associated factors of dental caries among adult population was 33\% [3]. Similar study, conducted at Nawalparasi, Nepal had reported that the oral health of the children was poor, chiefly dental caries remained widespread among children in school. Among all children, 86.1\% (95\% CI: 82.6-89.1) used toothpaste to brush their teeth [14].

However in this study, 20 (7.3\%) students did not use tooth paste and $95(34.7 \%)$ used tooth paste without fluoride and only $156(56.9 \%)$ used toothpaste with fluoride. Similar to our study, most of the participants brushed their tooth once per day which was the main factor to cause dental caries because after eating and drinking, if teeth is not cleaned, there
Table 1I Frequency table of socio-demographic characteristics of participants and predisposing factors $(\mathrm{n}=274)$

\begin{tabular}{|c|c|c|}
\hline Characteristics & Frequency & Percentages \\
\hline \multicolumn{3}{|l|}{ Age (years) } \\
\hline $6-8$ & 39 & 14.2 \\
\hline $8-10$ & 81 & 29.6 \\
\hline $10-12$ & 154 & 56.2 \\
\hline \multicolumn{3}{|l|}{ Gender } \\
\hline Female & 137 & 50.0 \\
\hline Male & 137 & 50.0 \\
\hline \multicolumn{3}{|l|}{ Parents education level } \\
\hline Below secondary & 116 & 42.3 \\
\hline Secondary level & 79 & 28.8 \\
\hline Secondary and above & 79 & 28.8 \\
\hline \multicolumn{3}{|l|}{ Food consumption habit } \\
\hline Normal food & 176 & 64.2 \\
\hline Junk food & 56 & 20.4 \\
\hline Spicy food & 39 & 14.2 \\
\hline \multicolumn{3}{|l|}{ Type of brush used } \\
\hline No brush used & 5 & 1.8 \\
\hline Hard type & 35 & 12.8 \\
\hline Medium type & 124 & 45.3 \\
\hline Soft type & 110 & 40.1 \\
\hline \multicolumn{3}{|l|}{ Type of toothpaste used } \\
\hline No use of tooth paste & 20 & 7.3 \\
\hline Non- fluoride tooth paste & 95 & 34.7 \\
\hline Tooth paste with fluoride & 156 & 56.9 \\
\hline \multicolumn{3}{|l|}{\begin{tabular}{|l|} 
Visit to dentist \\
\end{tabular}} \\
\hline No at all & 179 & 65.3 \\
\hline Once a year & 67 & 24.5 \\
\hline Twice a year & 28 & 10.2 \\
\hline \multicolumn{3}{|l|}{$\begin{array}{l}\text { Average time of teeth } \\
\text { brushing }\end{array}$} \\
\hline $0-2 \mathrm{~min}$ & 105 & 38.3 \\
\hline 2-5 min & 147 & 53.6 \\
\hline 5 min or more & 22 & 8.0 \\
\hline \multicolumn{3}{|l|}{$\begin{array}{l}\text { Changing time of new } \\
\text { brush }\end{array}$} \\
\hline In a year & 111 & 40.5 \\
\hline Every six month & 148 & 54 \\
\hline Every three month & 15 & 5.5 \\
\hline \multicolumn{3}{|l|}{$\begin{array}{l}\text { Bleeding while brushing } \\
\text { teeth }\end{array}$} \\
\hline Yes & 128 & 46.71 \\
\hline No & 146 & 53.28 \\
\hline
\end{tabular}

is chance of plaque formation quickly by the fermentable bacteria called Streptococcus mutans and the first stage of tooth decay can begin [3]. Almost half 124 (45.3\%) used medium type of brush and $110(40.1 \%)$ used soft type of brush for brushing their teeth, $20(7.3 \%)$ of the participants did not use tooth paste ,95 (34.7\%) used tooth paste without 
fluoride and 156 (56.9\%) used toothpaste with fluoride which is similar to the results of study conducted among indigenous population (Chepang community in Nepal) where, $86 \%$ of the children reported using toothbrush and toothpaste to clean their teeth, $61 \%$ of children reported to have received oral health education and $82 \%$ children did not know about fluoride and its benefit on dental health. Frequency of sugar exposure was low; $75 \%$ of children reported eating sugar rich food once daily [16]. Based on bivariate analysis to find associated factors of dental caries, it was found from chi-square test, that there was no association between frequency of dentist visit and dental caries at $(p=0.007)$. This may be because children do not follow the instructions given by the dentist properly.

However, this study shows there is strong association between frequency of brushing and dental caries $(p=0.001)$ at 95 CI. Children who brush their teeth twice a day had less dental caries. Moreover, this study found that there was no association between pain in teeth and dental caries $(\mathrm{p}=0.008)$, which might be because of recall bias; children forget their pain at the time of interview. A study which was carried out

\section{CONCLUSIONS}

Frequency of brushing, type of tooth brush and tooth paste, sex, type of food intake, monthly family income are the factors associated with dental caries. Mass campaign regarding oral health on regular basis could provide health education in adequate amount to school children and community people. Strategic in Riyadh, Saudi Arabia found that the associated factors of dental caries like irregular brushing, late adoption of brushing habit, consulting dentist for symptomatic treatment, lack of breast feeding, sleeping with a bottle in mouth, habit of snacking between meals, low consumption of fruits, and frequent consumption of soft drinks and flavored milk, were predominantly associated with dental caries in children, instead of socio-economic factors ( $p<0.05$, adjusted $R$-square $80 \%$ ) [9]. The findings on consumption of food in this study urges to adopt healthy eating practice at school level. A study reported that eating patterns and food choices play an important role in dental caries experience in children. Also, there was association between flavoured milk and dental caries based on the evolving trends in milk consumption practices in Saudi Arabia [9].

The study covered only 4 basic schools ( 2 public, and 2 private) inside the Kathmandu metropolitan city so, this study could not include children who were not admitting in the school. The results of this study is one-time assessment only, this could over and under estimate the findings.

plan at school definitely influences the diet and habit of regular and proper brushing techniques. Regular health education on oral hygiene, brushing, toothpaste and other oral hygiene related events from school to the students will improve the oral health status among school children.

\section{ADDITIONAL INFORMATION AND DECLARATIONS}

Acknowledgements: The authors would like to thank all individuals who rendered help and participated during the study period.

Funding: Self

Competing Interests: The authors declare no competing interests

\begin{abstract}
Author Contributions: Concept and design: MG, SKP; statistical analysis: MG, HPO; writing of the manuscript: MG, SKP, HPO and SG; revision and editing the manuscript: MG, SKP, HPO and SG. All authors read and agreed with the contents of the final manuscript.

Data Availability: Data will be available upon request to corresponding authors after valid reason.
\end{abstract}

\section{REFERENCES}

1. Alm A. On dental caries and caries-related factors in children and teenagers. Swed Dent J Suppl.2008;(195):7-63.

2. Martolia HCS. Prevalence and factors associated with dental caries nanintal India: Sree Chitra Tirunallnstitute for Medical Sciences and Technology. 2004.

3. Yadav K, Prakash S, Khanal S, \& Singh J. Prevalence of Dental Caries among adolescence of
Dhanusha

District,

Nepal. Janaki Medical College Journal of Medical Science. 2016;3(2):29-37.

4. Mulu W, Demilie T, Yimer M, Meshesha K, Abera B. Dental 
caries and associated factors among primary school children in Bahir Dar city: a crosssectional study. BMC Res Notes. 2014;7:949.

5. Moreira RdS. epidemiology of dentak caries in world. epideimogy of dental caries in world. 2012; 29340.

6. Haque SE, Rahman M, Itsuko K, Mutahara M, Kayako S, Tsutsumi A, Islam MJ, Mostofa MG. Effect of a school-based oral health education in preventing untreated dental caries and increasing knowledge, attitude, and practices among adolescents in Bangladesh. BMC Oral Health. 2016;16:44.

7. Bhagat T. and Shrestha A. Prevalence of dental caries among public school children in the Eastern Nepal. Journal of Chitwan Medical College. 2014:30-32.

8. Prasai Dixit L, Shakya A, Shrestha M, Shrestha A. Dental caries prevalence, oral health knowledge and practice among indigenous Chepang school children of Nepal. BMC Oral Health. 2013;13:20.

9. Nurelhuda, N.M., Trovik, T.A., Ali, R.W. et al. Oral health status of 12-year-old school children in Khartoum state, the Sudan; a school-based survey. BMC Oral Health 2009;9:15.

10. Santosh khanal ky. prevalance of dental caries among adolescence of dhanusha district Nepal. 2014.

11. Kabasi S, Tangade P, Pal S, Sah AF. Dental caries and oral health behaviour in 12-year-old school children in Moradabad city, Uttar Pradesh, India. J Indian Assoc Public Health Dent. 2014;12:167-72.

12. Arangannal $P$, Mahadev SK, Jayaprakash J. Prevalence of Dental Caries among School Children in Chennai, Based on ICDAS II. J Clin Diagn Res. 2016;10(4):ZC09-12.
13. Nurelhuda, N.M., Trovik, T.A., Ali, R.W. et al. Oral health status of 12-year-old school children in Khartoum state, the Sudan; a school-based survey. BMC Oral Health 2009;9:15.

14. Thapa P, Aryal KK, Dhimal M, Mehata S, Pokhrel AU, Pandit A, Pandey AR, Bista B, Dhakal P, Karki KB, Pradhan S. Oral Health Condition of School Children in Nawalparasi District, Nepal. J Nepal Health Res Counc. 2015;13(29):7-13.

15. Moreira, Rafael. Epidemiology of Dental Caries in the World. 2012.

16. Prasai Dixit L., Shakya A., Shrestha M. et al. Dental caries prevalence, oral health knowledge and practice among indigenous Chepang school children of Nepal. BMC Oral Health. 2013;13:20. 